\title{
An Investigation of Residents' Perceptions of Positive Festival Impacts, Community Attachment and Well-being: A Study on the Jameson Festival, Victoria Falls, Zimbabwe
}

\author{
Cathrine Banga', Hasan Kilic ${ }^{2}$, Stewart Musarapasi ${ }^{3}$ \\ ${ }^{1}$ Msc Tourism and Hospitality Management, (PhD Candidate), Eastern Mediterranean \\ University, Turkey, e-mai: 17600083@emu.edu.tr \\ 2Professor, Dean - Faculty of Tourism, Eastern Mediterranean University, Turkey, \\ e-mail: hasan.kilic@emu.edu.tr \\ ${ }_{3}^{3}$ MBA, Student (PhD Candidate), Near East University, Turkey, \\ e-mai: stewartmsp@gmail.com
}

\begin{abstract}
The Study aims to examine residents' perception of positive festival impacts, social cohesion and cultural benefits on the relationship between community attachment and wellbeing. An integration of the Social Exchange and Affect Theories are employed to develop and test a conceptual model that test the interrelationships. The quantitative research approach is used to conduct the study on resident attendees of the Jameson Festival in Victoria Falls, Zimbabwe. Via the convenience sampling technique data are collected. Results of the study indicate that festivals foster community cohesiveness and community attachment. They also show that the perceived positive festival impact: community cohesiveness is strongly related to community attachment and well-being; community attachment mediates the relationships. Contrarily, though the relationship between festival cultural preservation and community attachment was partially supported, there was no significant association to well-being. The theoretical implications of the study lay mainly on the introduction of a new theory to the festival body of studies and the study' findings shed light and direction on practical implications and future directions for festival organizers and scholars.
\end{abstract}

Keywords: Community Attachment, Community Cohesion, Cultural Preservation, Festival, Well-being, Victoria Falls, Zimbabwe.

JEL code: $M 30$.

Received: 22 July 2021 Revised: 1 October 2021 Accepted: 9 November 2021

Published: 10 December2021

\section{Introduction}

The past decades have seen growth in festivals become tourist attractions (Luna, 2015), and emerge as exciting sectors of the tourism industry, posing significant economic, socio-cultural, and political impacts within host communities (Arcodia, Whitford, 2006; Song et al., 2015). Notably, there has been a number of destinations globally investing in festivals (Asero, Tomaselli, 2021), similarly, the case with Zimbabwe. Seen as crucial motivators of tourism embodying significant elements towards 
marketing plans and developments of destinations (Asero, Tomaseli, 2021), festivals serve different purposes to host communities.

Previous studies show that festivals positively affect a destination's image (Lee et al., 2005; Luna, 2015), enhance the self- image of the local population (Quinn, 2006). Local festival developments increase cultural tourism and provide the tourist destination with economic and cultural benefits (Luna, 2015). Additionally, festivals enhance community well-being, community cohesion, enhance pride, community identity (Derret, 2003), foster the sense of community (Van Winkle, Woosnam, 2013; Yu, Ke, 2010), improve residents' well-being (Yolal et al., 2016), emotional solidarity and community attachment (Li, Wan, 2014) as well as residents' support to local events (Prayag et al., 2013).

In view of the above arguments and how festivals increase interest and growth in several destinations, a need to understand residents' perceptions of festival impacts and their effects on communities' well-being arise. Most studies make general reports on festival impacts (socio-cultural and economic) with less attention given to other festival benefits: community cohesion and culture preservation. Moreover, suggestions to further investigate the relationship between perceived festival impacts and residents' well-being (Yolal et al., 2016) are called for. Literature suggests that festivals foster community attachment (Li, Wan, 2014) and promote community identity and social cohesion amongst residents (Yolal et al., 2016). Community attachment though not new to festival studies, has mostly been explained from a festival visitor perspective in relation to satisfaction and behavioural intentions (Lee et al., 2014), with little known from a resident's perspective.

Improving residents' well-being has been the main focus of many public policies and governments (Dolan, Metcalfe, 2012). Organ et. al., (2015) indicate that festivals promote social interactions and social relationships that have the ability to improve residents' well-being and enhance a sense of belonging (Cohen, 2004). Although research has confirmed that festivals enhance subjective well-being of local residents, Diener and Diener (2009) denotes that there is still a little understanding regarding residents' participation in festivals and how it influences subjective well-being and quality of life. Suggestions are also made to investigate residents' perceptions of festival social impacts and their relationship to quality of life (Hao et al., 2011; Yolal et al., 2016).

On this milieu, the research objectives implicated investigate the relationships between perceived positive festival impacts (community cohesion and culture preservation), community attachment and residents' well-being. The study also analyses the mediating role of community attachment on the interrelationships. The study contributes to literature by 
developing and testing a conceptual model that investigates the effects of festival benefits on the aforementioned interrelationships. It introduces community attachment as a mediator. And it uses theoretical frameworks to investigate residents' perceived festival impacts in a host community (Van Winkle, Woosnam, 2014). Finally, a new theory (Affect theory) is introduced to further explain the interrelationships.

\section{Literature review}

Two theories are used in this study to develop hypotheses on the proposed interrelationships. The social exchange theory (SET) analyses social behaviours and observes them as a process (Van Winkle, Woosman, 2014), working on a comparison of relationships. That is, one's ability to weigh and assess the benefit they get from a relationship given their input towards it. SET assumes that people are likely to take part in an exchange, given they benefit something from it, without accruing fees (Prayag et. al., 2013). Past studies confirm the assertions, as it was noted that residents assessed events based on perceived positive and negative impacts of costs (Li, Wan, 2017) and individuals positively viewed tourism upon experiencing higher benefits of an event (Van Winkle, Woosman, 2014).

In line with Andriotis and Vaughan's (2003) interpretation of the theory, this study adopts SET, on the assumption that when residents perceive positive festival benefits, communities develop attachment, ultimately leading to improved lifestyles. SET, however, has known limitations (Prayag et al., 2013; Song et al., 2015), thus the use of integrative approaches; use of Affect Theory in the current study.

\section{Affect Theory (AT)}

The Affect Theory evaluates the emotions and feelings experienced by individuals given a certain action or encounter. The theory implies that people react in a certain way given that certain emotions within them are aroused. AT tries to understand what brings people together in a community and how people relate to their surroundings (d'Haustere, 2015). The theory has been used to evaluate social relations in tourist destinations (d'Haustere, 2015). Ettinger (2006) viewed affect as a relational force. The theory helps understand human being social links, how they bring individuals together towards a common identity (Ettinger, 2006). d'Haustere's (2015) study notes that tourist destinations provide several prospects for visitors to develop affect. Tourists look for social capital and create collective identity at a destination. Similarly, this research suggests that festivals have the ability to create social capital for residents in a host community, hence the capacity to develop affect which leads to community attachment. The theory, 
although new to festival settings, helps understand residents' actions based on how they perceive festival impacts, and how their perceptions influence community attachment and residents' well-being.

\section{Perceived Festival Impacts (Benefits: Community Cohesion \& Cultural Preservation) and Community Attachment}

Community cohesion concerns bringing people together by developing strong relationships amongst people while collectively gathering to share a common value. It promotes peace, and fosters a sense of belonging by advocating for community networking. Cohesion prompts harmony in communities and improves residents' quality of Life (Britannica, 2013). Festivals motivate social cohesion as they strengthen relationships within communities (Gursoy et al., 2004; Rao, 2001). In light of the arguments above, a conclusion is made that, social networks, a sense of belonging, community identity and pride predict social community cohesion, making community attachment inevitable. Festivals are developed for the purpose of preserving culture (Yolal et al., 2016). They portray the cultural wealth of a destination and give rise to the development of cultural activities in host communities. Accordingly, festivals allow communities to promote and sustain their culture through prolonged displays and participation in traditional activities (Black, 2016).

Festival benefits relate highly to community attachment. Community attachment is noted as a socio-economic factor (Besculides et al., 2002). Thus, when festival impacts are perceived as beneficial to a host community, community pride, community elements, a sense of belonging and social cohesion are developed. The SET and Affect theories are used to further understand the relationships between positive festival impacts and community attachment. SET has proven that the higher the involvement of individuals in tourism developments, the more positive perceptions are viewed (Van Winkle, Woosnam, 2014). Affect connects people or to a place, thus helping us understand the relations between residents and their community. As highlighted in d'Haustere (2015), affect is a strong force for social networks and it creates cohesion. It therefore is asserted that when residents perceive positive festival impacts, cohesion which leads to attachment is created. Once positive benefits such as socio-cultural and economic impacts, cohesion and cultural preservation are experienced, residents are motivated to come together towards a common goal. With the forgoing discussion in mind, two hypotheses are constructed:

$\mathrm{H}_{1}$ : Community cohesiveness is related to community attachment.

$\mathrm{H}_{2}$ : Cultural preservation interrelates with community attachment. 


\section{Perceived Festival Impacts (Benefits) and Residents' Wellbeing}

The term well-being is the state of comfort experienced by one which entails security and happiness. It comprises two factors; the affective feeling and cognitive assessment of one's life (Diener, Suh, 1997). Well-being is the outcome of one's emotional reactions to events, the cognitive evaluations of satisfaction and fulfilment that events bring to people's lives (Yolal et al., 2016). According to Diener and Suh (1997), satisfaction, pleasant affect and low levels of pleasant affect measure well-being. While, literature suggests that festival new experiences develop satisfaction (Liburd \& Derkzen, 2009). Festivals foster community and cultural/educational benefits, socio-cultural festival impacts believed to improve residents' well-being and quality of life (Yolal et. al., 2016).

Festivals are considered a positive tourism development with the ability to create economic benefits through government tax revenues, employment, increased business prospects, and generation of extra revenue for the host nations (Derrett, 2003; Yolal et al., 2016). Moreover, it is also noted that festivals strengthen social ties, cohesion and pride in communities (Gursoy et al., 2004; Herrero \& Gracia, 2011; Rao, 2001; Yolal et al., 2016). With the above notions in mind, propositions are made that community cohesion contributes to the well-being of festival attendees. Alluded earlier, festivals promote cultural preservation. For example, studies prove that festivals provide an integral amount of cultural and educational benefits which have significant positive effects on residents' well-being (Yolal et al., 2016). Therefore, the following hypotheses are developed:

$\mathrm{H}_{3}$ : Community cohesion positively relates to well-being.

$\mathrm{H}_{4}$ : Cultural preservation associates with well-being.

\section{Community Attachment and Residents' Wellbeing}

Community attachment can be referred to as a sense of belonging, common identity and the willingness to take part in social activities. It is an affective bond or an emotional attachment between individuals and their community (Lee, 2013). Literature opines that social bonds (Goudy, 1990), sense of community (Goudy, 1990; Williams et al., 1995), community pride and community elements (Baker, Palmer, 2006) determine community attachment. It is argued that when individual develop a sense of belonging and identify strongly with its community, attachment and commitment thereof on any matter arising in the community become easy (Lee et al., 2014). Some studies noted that positive and negative attitudes on festivals affect community attachment (Li, Wan, 2014), while some noted that CA as a social and economic factor affects residents' attitudes and perceptions towards tourism development (Besculides et. al., 2002). 
The more residents take part in festivals and realize positive benefits, the more they develop a sense of belonging and feel the need to work together towards a common goal. Thus, when community attachment is developed, community pride is built amongst residents in a host community, and when the social ties are perceived beneficial, residents' well-being is also improved. In agreement, Baker and Palmer (2006) purport that factors such as community pride and community elements are major predictors of quality of life. Additionally, studies indicate that community attachment influences residents' perceptions towards tourism development (Li, Wan, 2017). Given the empirical evidence, the following hypothesis is constructed:

$\mathrm{H}_{5}$ : Community attachment is related to residents' well-being.

\section{Community attachment as a Mediator}

SET helps understand residents' attitudes towards development in host communities. It is believed that when residents identify positive festival impacts, inspiration to participate further in events may be drawn, thus increasing community attachment and eventually residents' well-being. When residents highly regard festivals and perceive them beneficial to the community, the more the people desire to work together, thereby developing social bonds and community elements that contribute to social cohesion and community attachment. It is also reasonable to suggest that once positive benefits are highly perceived, communities easily recognize vital resources such as culture preservation and they endeavour to sustain it, a process that brings helps create social cohesion and attachment. A working and peaceful community brings joy and satisfaction which are indicators for well-being. Furthermore, d'Haustere (2015) suggests that affect develops social connections and/or social relations that lead to action. Based on residents' perceived impacts, affect develops cohesions in the same way affect attracts tourists to a destination. Therefore, affect theory helps us understand how residents connect with each other when they perceive benefits, create attachment to a place, thereby adding value to their lives. The following hypotheses are thus constructed:

\footnotetext{
$\mathrm{H}_{6}$ : Community attachment mediates the relationship between community cohesion and residents' wellbeing.

$\mathrm{H}_{7}$ : Community attachment mediates the relationship between cultural preservation and residents' wellbeing.
} 


\section{Conceptual Model}

Based on the notions that festivals greatly contribute to and benefit host communities, the proposed conceptual model of the study is presented below.

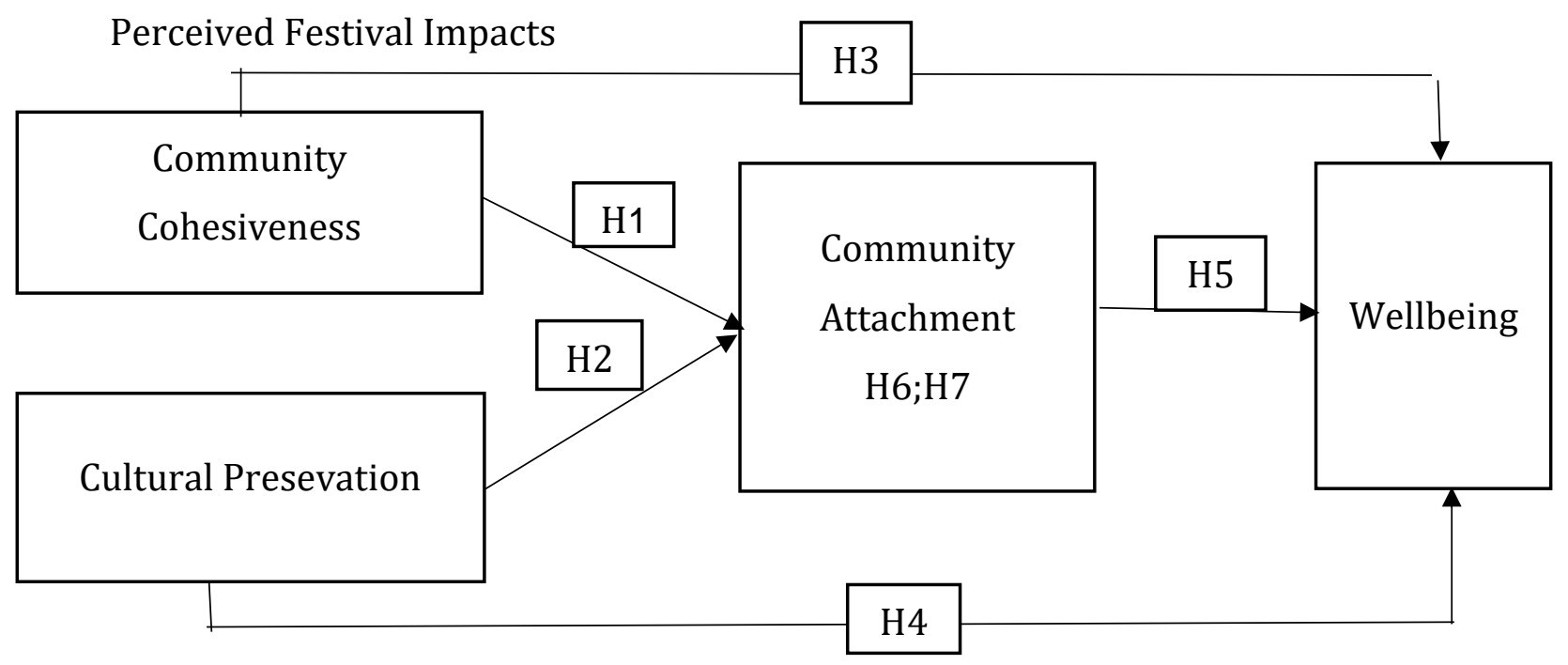

Fig.1. Conceptual Model

\section{Methodology}

Data were gathered from residents of Victoria Falls, Zimbabwe, the host destination of the Jameson Festival. Termed "Africa's largest new year celebrations", it is a three-day music event running every year from the $29^{\text {th }}$ - 31 $1^{\text {st }}$ of December. Deductive approach research methods were used to develop and test the conceptual model. While convenience sampling which relies on data collection from members conveniently available to take part in the study (Saunders et al., 2012) were engaged for the study. Data were collected through self-administered questionnaires after a pilot study was conducted with 20 residents in Victoria Falls, Zimbabwe. Questionnaires were completed onsite, and of the 500 questionnaires distributed, 346 were returned.

Perceived benefits were measured using seven parameters (Song et al., 2015), consistent with (Gursoy, Kendall, 2006; Jackson, 2008; Liu, 2009; Lorde et al., 2011; Small et al., 2005; Zhou, Ap, 2009). Four items were used to measure community attachment (Li, Wan, 2013) adopted from literature (Sheldon, Var, 1984; Williams et al., 1995), and three items were used to measure residents' well-being (Yolal et al., 2016).

The research was conducted in March 2017, two months post the Jameson festival consistent with Li and Wan (2017), Pranić, Petrić, and Cetinić (2012), Song et al. (2015), and Van Winkle and Woosnam (2014). For ethical reasons, respondents were briefed on the purpose of the study and 
they were assured of anonymity and confidentiality. Eligible respondents had to be eighteen years of age and above, be residing in Victoria falls for at least a year and over since festival inception and should have attended the Jameson festival at least once. Such criteria were considered in previous studies (Li, Wan, 2017; Prayag et al., 2013; Yolal et al., 2016).

Frequencies were used to show the demographic profile of the respondents. Convergent and discriminant validity were assessed through exploratory factor analysis and Pearson correlation. Each variable's Coefficient alpha (Nunnally, 1978) is reported with the significance level of .70. The hypothesized relationships were assessed via hierarchical multiple regression analysis in line with Baron and Kenny's (1986) guidelines in order to gauge the mediating effects. The Sobel test was used to report the significance of the mediating effects.

\section{Results}

\section{Respondents' Profile}

The study shows that more men participated in the festival (52\%) than women $(48 \%)$, and $63 \%$ of the participants were either single or divorced while rest were married (36.7\%). Most respondents (57.5\%) were between the ages of $28-37 ; 38-47(22.6 \%), 18-27(17.2 \%)$ and the rest of the participants at $2.7 \%$ were above the age of 48 . The majority of the residents were formally educated, $45 \%$ of the participants had a university degree, had received vocational training (35.5\%) and or a high school qualification (14\%) and at least 3.9\% held a masters' or PHD qualification, and the rest of the residents had reached as far as primary level education. The participating residents had to be residing in the host destination for over a year and above post festival commencement.

\section{Exploratory Factor Analysis and Correlations}

In order to assess convergent and discriminant validity, an exploratory factor analysis (principal component analysis) with Varimax rotation and reliability analysis were performed. The five indicators in the model explained $79 \%$ of the variance. All of the items had factor loadings of 0.70 and above and loaded onto their underlying constructs. All Eigen values were greater than 1.00. All coefficients Alpha were higher than the cut-off level 0.60. Specifically, festival impacts (cultural preservation and community cohesiveness) and community attachment reported a Cronbach Alpha of $0.87,0.74$, and 0.91 . Cronbach Alpha for WLB is reported at 0.89 , which shows that all the scales were reliable. Therefore, convergent validly and discriminant was established. 
Table 1 Scale Items, Exploratory Factor Analysis and Internal Consistency Reliability (compiled by the authors)

\begin{tabular}{|c|c|c|c|c|}
\hline Scale items & Factor Loadings & Eigen values & $\%$ of the variance & $\alpha$ \\
\hline $\begin{array}{l}\text { IMPCB } \\
\text { Cult Preserve }\end{array}$ & & 3.68 & 28.37 & 0.87 \\
\hline 1 & .95 & & & \\
\hline 2 & .92 & & & \\
\hline 3 & .76 & & & \\
\hline 4 & .75 & & & \\
\hline COMATT & & 2.94 & 22.60 & 0.91 \\
\hline 1 & .93 & & & \\
\hline 2 & .92 & & & \\
\hline 3 & .86 & & & \\
\hline WLB & & 1.96 & 15.04 & 0.89 \\
\hline 1 & & .93 & & \\
\hline 2 & & .90 & & \\
\hline 3 & & .87 & & \\
\hline MPCB Com coh & & 1.70 & 13.00 & 0.74 \\
\hline 1 & .85 & & & \\
\hline 2 & .82 & & & \\
\hline 3 & .79 & & & \\
\hline
\end{tabular}
Sphericity $=2413.979, \mathrm{p}<.001 . \alpha-$ Coefficient alpha; IMPBC CultPreserv = Impact (benefit) Cultural preservation; COMMATT $=$ Community attachment; WLB = Wellbeing; IMPCB Comcoh = Impact (benefit) community cohesiveness.

Table 1 presents the correlation coefficients among the study variables which are below .70. Means, a standard deviation, and correlations of the variables are also shown in Table 2. The first three conditions for mediation analysis (Baron, Kenny, 1986) are achieved, as the main correlations among the study variables are significant. Firstly, there is a significant correlation between community cohesiveness and cultural preservation $(r=-.151)$ and community attachment $(\mathrm{r}=-.258)$ based on the first condition. Table 4 which presents regression results also supports these direct relationships. There is a significant correlation between community cohesiveness and well-being ( $\mathrm{r}$ $=.206$ ) but not between cultural preservation and well-being. The significant relationship between the independent and the criterion variable supports the second condition. The third condition regarding the relationship between the mediator and the criterion variable is also met only for community attachment and well-being $(r=.236)$. As there is no significant association between well-being and cultural preservation, cultural preservation is not included in the mediation analysis. 
Table 2 Mean and Standard Deviations of and Correlations between the Variables (compiled by the authors)

\begin{tabular}{|l|c|c|c|c|}
\hline \multicolumn{1}{|c|}{ Variables } & 1 & 2 & 3 & 4 \\
\hline 1 WLB & 1000 & & & \\
\hline 2 COMATT & $.236^{* *}$ & 1000 & & \\
\hline 3 CULTPRES & -.009 & $-.151^{* *}$ & 1000 & \\
\hline 4 COMCOH & $.206^{* *}$ & $.258^{* *}$ & -.022 & 1000 \\
\hline Mean & 2.76 & 6.47 & 2.07 & 4.07 \\
\hline Standard deviation & 0.78 & 0.67 & 0.64 & 0.56 \\
\hline
\end{tabular}

Notes: Each variable's composite scores were obtained by averaging scores across items representing the measure. ${ }^{* *}$ Correlation significant at the 0.01 level. $W L B=$ Wellbeing; COMMATT = Community attachment; CULTPRES = Cultural preservation; $C O M C O H=$ Community cohesiveness.

\section{Model Results}

Table 3 presents the direct effects of the study's variables. Hypothesis 1 puts forward that community cohesiveness is positively related to community attachment. This hypothesis is supported as shown in Table 3, as community cohesiveness has a significant influence on community attachment $(\beta=.258, \mathrm{p}<0.001)$. Hypothesis 2 puts forward that cultural preservation is related to community attachment. Cultural preservation has a significant negative impact on community attachment $(\beta=-.151, p<0.010)$ shown in Table 3; therefore, hypothesis 2 is partially supported. Hypothesis 3 puts forward the effect of community cohesiveness on well-being. Hypothesis 3 is supported $(\beta=.206, p<0.001)$. Hypothesis 4 is not supported because cultural preservation is not related to well-being. Hypothesis 5 which denotes the relationship between community attachment and wellbeing is also supported. Hypothesis 6 is supported as community attachment plays a mediating role between community cohesiveness and well-being as shown in Table 4 . That is, community attachment partially mediates the effect of community cohesiveness on well-being, and the increment in $\mathrm{R}^{2}$ of the model $\left(\Delta R^{2}=.036, \mathrm{p}<0.001\right)$. The Sobel test also provides support for well-being as a partial mediator of the influence of community attachment on community cohesion ( $\mathrm{t}=2.54, \mathrm{p}<0.01)$. Hypothesis 7 is not supported, as cultural preservation was not included in the mediation analysis due to its non-significant effect with well-being. 


\section{Table3 Hierarchical Multiple Regression Analysis Results: Direct Effects (compiled by the authors)}

\begin{tabular}{|c|c|c|c|c|c|c|c|c|c|}
\hline \multirow[t]{2}{*}{ Variable } & \multicolumn{2}{|c|}{$\begin{array}{l}\text { Community } \\
\text { attachment }\end{array}$} & \multicolumn{2}{|c|}{ Wellbeing } & \multirow[t]{2}{*}{ Variable } & \multicolumn{2}{|c|}{$\begin{array}{l}\text { Community } \\
\text { attachment }\end{array}$} & \multicolumn{2}{|c|}{ Wellbeing } \\
\hline & $\boldsymbol{\beta}$ & $\mathbf{t}$ & $\boldsymbol{\beta}$ & $\mathbf{T}$ & & $\boldsymbol{\beta}$ & $\mathbf{t}$ & $\beta$ & $\mathbf{t}$ \\
\hline СOMCOH & .258 & $4.86^{* *}$ & .206 & $3.82^{* *}$ & CULTPRES & -.151 & $-2.77^{* *}$ & -.009 & -.158 \\
\hline $\mathbf{F}$ & 23.59 & - & 14.58 & - & & 7.66 & - & 0.25 & - \\
\hline $\begin{array}{l}R^{2} a t \text { each } \\
\text { step }\end{array}$ & .07 & - & .04 & - & & .03 & - & .00 & - \\
\hline$\Delta R^{2}$ & - & - & - & - & & - & - & - & - \\
\hline
\end{tabular}

${ }^{* *} \mathrm{p}<0.001,{ }^{*} \mathrm{p}<0.10$, figures in parentheses represent the $\mathrm{t}$-values

\section{Table 4 Hierarchical Multiple Regression Analysis Results: Indirect} Effects (compiled by the authors)

\begin{tabular}{|l|c|c|}
\hline \multicolumn{3}{|c|}{ Dependent variable and standardized regression weights } \\
\hline Independent variables & WLB & Step2 \\
COMCOH & Step1 & $.16(2.83)^{*}$ \\
COMATT & $.21(3.82)^{* *}$ & $.19(3.57)^{* *}$ \\
F & 14.58 & 13.93 \\
$\boldsymbol{R}^{2} \boldsymbol{a t}$ each step & .042 & .078 \\
$\boldsymbol{\Delta R}^{2}$ & & .036 \\
\hline
\end{tabular}

Sobel test: COMATT $\longrightarrow$ WLF $\longrightarrow$ COMCOH $3.04, \mathrm{p}<0.05$

Note: The results do not show any problems of multicollinearity, ${ }^{*} \mathrm{p}<0.05,{ }^{* *} \mathrm{p}<0.001$, figures in parentheses represent the t-values; $\mathrm{COMCOH}=$ Community cohesiveness; COMATT $=$ Community attachment; WLB = Wellbeing.

\section{Discussion}

Of the seven hypotheses constructed, four hypotheses were fully supported, one was partially supported and two were not supported. The results indicate that positive festival impacts (benefits): community cohesiveness and cultural preservation to some extent had effects on community attachment, and community cohesiveness is positively connected to community attachment. The result was consistent with other researchers suggesting that positive festival impacts yields community attachment (Li, Wan, 2013) and community pride (Mill, Morris, 2002), and Getz (1997).

Culture preservation, considered a positive festival impact (Besculides et al., 2002; Black, 2016; Van Winkle, Woosnam, 2014; Yolal et al., 2009; Yolal et al., 2016) in this study had negative effects on community attachment. Reasons to this outcome are not quite known, although assumptions are made that, in the case of the Jameson Festival, negative results may have been 
due to the fact that the event is still fairly new to the community. Residents may not have known that cultural practices in events yield benefits to their community. Inconsistent cultural practices, less attention to cultural issues and presentation during festivals lead to negative perception. The above notions are supported in Black's (2016) study which noted the need for festivals to enhance cultural activities.

Consistent with Yolal's et. al. (2016) findings that positive festival impacts positively affected residents well-being, the current study findings also showed that community cohesiveness positively affected residents' well-being. Further findings in the study confirm a significant relationship between community cohesiveness and residents' well-being, with no relationship whatsoever between cultural preservation and residents' wellbeing. Community harmony as noted earlier is an indicator for a desired high life standard and/or one's well-being. The result also supports the findings of Gursoy et al. (2004) and Dwyer et al. (2000) who suggest that festivals and events are a significant factor for the communities.

Preserving culture was not seen to contribute towards well-being. This finding is contrary to what literature holds, as many studies have noted cultural preservation to contribute to social cohesion (Black, 2016; Highmore, 2016) amongst residents within a host community and wherein social ties are meant to bring harmony that in turn contribute to the residents' well-being (Yolal et al., 2016). Research generally notes that positive and/or negative impacts are inevitable, however, it may also be that some events may or may not foster these effects (Ohmann et al., 2006). The results also suggest that community attachment positively relates to wellbeing. Supporting the study findings, Goudy (1990) notes, a sense of belonging, social bonds and a sense of community as antecedents of community attachment believed to contribute toward well-being.

Lastly, the study results indicate that community attachment mediates the relationship between festival impact (community cohesiveness) and residents' well-being. As alluded before, festivals foster cohesion and attachment among individuals in a community. Once residents positively perceive impacts of an event or experience benefits from it, courage and confidence to participate more in the event is built. As the people interact during the festivals, social ties are developed contributing to social cohesion eventually leading to an affection and attachment towards the community. When people begin to work together in agreement over the same issues, peace is developed, an antecedent for well-being.

\section{Theoretical Implications}

The developed theoretical framework helps assess the effect of residents' perceptions on community attachment and well-being. In the case 
of SET, an exchange process takes place among residents. Residents become more attached to their community when and if they perceive more positive festival impacts (community cohesiveness). When more negative festival impacts are viewed, likewise residents become less attached to the community, and do not feel nor think their lives are improved in any way as a result. The current study in line with other researchers further confirms this notion to be valid (Nunkoo, Ramkissoon, 2011; Li, Wan, 2017), as residents of Victoria Falls did not perceive any benefits in cultural preservation, hence the negative results on the relationship between the variable and community attachment and residents' well-being.

Furthermore, the current research study implements the affect theory (d'Haustere, 2015) in the context of festivals. Affect theory, helps understand what makes people come together, what attracts them to festivals and to take part in the event. The results of the study prove that residents become more attached to their community when they perceive positive festival impacts (community cohesiveness) as compared with when the impacts are negative (e.g., cultural preservation). The study introduces community attachment as a mediator between festival impacts and residents' well-being.

\section{Practical Implications of the study}

The study offers a number of practical implications for the Jameson Festival organizers and other stakeholders involved in the planning, marketing and promotion of the event. Residents play a vital role in the commencement of festivals and its success, making them important stakeholders (Deery et al., 2012; Song et al., 2015). As such, involving host community residents in festival planning could be beneficial to the success of festivals. The results of the current study indicate that positive festival impacts (benefits: community cohesiveness) are associated with community attachment and residents' well-being. Festival organizers must publicize the anticipated festival benefits through various media and conducting of community meetings with residents to discuss the event and make preparations for it.

The study established community attachment as a mediator on the relationship between festival impacts and residents' well-being. As such, festivals could be built in ways that social ties, a sense of belonging and a sense of community are easily created within communities (e.g., via community involvement and participation). Organizers could increase pride among residents by giving them the honour to participate in the festival. The study's findings show that residents' well-being is mostly enhanced when locals have developed social community cohesion and attachment amongst themselves. Thus, festival organizers should design festivals in such a way 
that social ties, bonds, community pride cohesion and community attachment are enhanced.

\section{Limitations and Future Research}

This study pays attention to positive festival impacts, nevertheless including the negative perceived festival impacts may also be beneficial to further understanding the tested interrelationships. Two festival impacts (benefits: community cohesiveness and cultural preservation) are included in this study, other perceived impacts such as: community and educational benefits (Yolal et al., 2016), socio, cultural, economic, physical and environmental impacts on community attachment and well-being could be investigated. Furthermore, the study focused on community attachment as a mediator, future studies can implore other mediation mechanisms such as a sense of community (Yolal et al., 2016), social ties, community identity and pride.

\section{Conclusion}

The results show that festivals foster community cohesiveness and community attachment. Events as such are quite involving, hence their ability to help develop a sense of belonging and togetherness within host communities. The results also show that the perceived positive festival impact - community cohesiveness - is strongly related to community attachment and well-being and as such community attachment mediates their relationships. There is also a direct positive relation between community attachment and well-being. Although the relationship between festival cultural preservation and community attachment was partially supported, there was no significant association to well-being.

\section{References}

1. Andriotis. K., Vaughan. R.D. (2003). Urban residents' attitudes toward tourism development: The case of Crete. Journal of Travel Research, 42(2), 172-185.

2. Arcodia, C., Whitford, M. (2006). Festival attendance and the development of social capital. Journal of Convention \& Event Tourism, 8(2), 1-18.

3. Asero, V., Tomaselli, V. (2021). The Impact of an International Literary Festival in a Tourist Destination. In Handbook of Research on Cultural Heritage and Its Impact on Territory Innovation and Development (pp. 259-275). IGI Global.

4. Baker, D. A., Palmer, R. J. (2006). Examining the effects of perceptions of community and recreation participation on quality of life. Social Indicators Research, 75(3), 395418.

5. Baron, R. M., Kenny, D. A. (1986). The moderator-mediator variable distinction in social psychological research: Conceptual, strategic, and statistical considerations. Journal of Personality and Social Psychology, 51(6), 11-73. 
6. Besculides, A., Lee, M. E., McCormick, P. J. (2002). Residents' perceptions of the cultural benefits of tourism. Annals of Tourism Research, 29(2), 303-319.

7. Black, N. (2016). Festival connections: How consistent and innovative connections enable small scale rural festivals to contribute to socially sustainable communities. International Journal of Event and Festival Management, 7(3), 172-187.

8. Britannica, T. E. (2013). Ganesh Chaturthi. Retrieved from www.britannica.com/EBchecked/topic/225304/Ganesh-Chaturthi

9. Cohen, S. (2004). Social relationships and health. American Psychologist, 59(8), 676.

10. d'Hauteserre, A. M. (2015). Affect theory and the attractivity of destinations. Annals of Tourism Research, 55(6), 77-89.

11. Deery, M., Jago, L., Fredline, L. (2012). Rethinking social impacts of tourism research: A new research agenda. Tourism Management, 33(1), 64-73

12. Derrett, R. (2003). Festivals and regional destinations: How festivals demonstrate a sense of community \& place. Rural Society, 13(1), 35-53.

13. Diener, E. D., Suh, M. E. (1997). Subjective well-being and age: An international analysis. Annual review of gerontology and geriatrics, 17(1), 304-324.

14. Diener, E., Diener, M. (2009). Cross-cultural correlates of life satisfaction and selfesteem. In Culture and Well-being (pp. 71-91). Springer Netherlands.

15. Dolan, P., Metcalfe, R. (2012). Measuring subjective wellbeing: Recommendations on measures for use by national governments. Journal of Social Policy, 41(2), 409-427.

16. Dwyer, L., Mellor, R., Mistilis, N., Mules, T. (2000). A framework for assessing "tangible" and "intangible" impacts of events and conventions. Event Management, $6(3), 175-189$.

17. Ettinger, B. (2006). The matrixial borderspace (theory out of bounds). Minneapolis, MN: University of Minnesota Press.

18. Getz, D. (1997). Event management and event tourism. New York: Cognizant Communication.

19. Goudy, W. J. (1990). Community attachment in a rural region. Rural Sociology, 55(2), 178-198.

20. Gursoy, D., Kendall, K. W. (2006). Hosting mega events: Modeling locals' support. Annals of tourism research, 33(3), 603-623.

21. Gursoy, D., Kim, K., Uysal, M. (2004). Perceived impacts of festivals and special events by organizers: An extension and validation. Tourism Management, 25(2), 171-181.

22. Hao, H., Long, P., Kleckley, J. (2011). Factors predicting homeowners' attitudes toward tourism: A case of a coastal resort community. Journal of Travel research, 50(6), 627640.

23. Herrero, J., Gracia, E. (2011). Covariates of subjective well-being among Latin American immigrants in Spain: The role of social integration in the community. Journal of Community Psychology, 39(7), 761-775.

24. Highmore, B. (2016). Formations of feelings, constellations of things. Cultural Studies Review, 22(1), 144-167.

25. Jackson, L.A. (2008). Residents' perceptions of the impacts of special event tourism. Journal of Place Management and Development, 1(3), 240-255.

26. Lee, C. K., Lee, Y. K., Lee, B. (2005). Korea's destination image formed by the 2002 World Cup. Annals of Tourism Research, 32(4), 839-858.

27. Lee, I. S., Lee, T. J., Arcodia, C. (2014). The effect of community attachment on cultural festival visitors' satisfaction and future intentions. Current Issues in Tourism, 17(9), 800-812. 
28. Lee, T. H. (2013). Influence analysis of community resident support for sustainable tourism development. Tourism Management, 34(5), 37-46.

29. Li, X., Wan, Y. K. P. (2013). Residents' attitudes toward tourism development in Macao: A path model. Tourism Analysis, 18(4), 443-455.

30. Li, X., Wan, Y. K. P. (2017). Residents' support for festivals: Integration of emotional solidarity. Journal of Sustainable Tourism, 25(4), 517-535.

31. Li, X., \& Wan, Y.K.P. (2014, June). Residents' support for festivals: Integration of emotional solidarity. In Proceedings of theTTRA 45th Annual International Conference on Tourism and the New Global Economy (pp. 525-534), 18-20 June 2014,Brugge, Belgium. Whitehall, MI: Travel \& Tourism Research Association.

32. Liburd, J. J., Derkzen, P. (2009). Emic perspectives on quality of life: The case of the Danish Wadden Sea Festival. Tourism and Hospitality Research, 9(2), 132-146.

33. Liu, M. (2009). A research in the social impact of convention and exhibition activities on host cities (Unpublished doctoral dissertation). Jinan University, PR China.

34. Lorde, T., Greenidge, D., \& Devonish, D. (2011). Local residents' perceptions of the impacts of the CC Cricket World Cup 2007 on Barbados: Comparisons of pre-and postgames. Tourism Management, 32(2), 349-356.

35. Luna, A. M. (2015). A Festival's Impact: The case of the Bañamos festival. Researchers World, 6(1), 49.

36. Mill, R. C., Morrison, A. M. (2002). The tourism system, kendall. Hunt, Dubuque, Iowa.

37. Nunkoo, R., Ramkissoon, H. (2011). Developing a community support model for tourism. Annals of Tourism Research, 38(3), 964-988.

38. Nunnally, J. (1978). Psychometric theory. 2nd ed. New York, NY: McGraw-Hill Book Company.

39. Ohmann, S., Jones, I., Wilkes, K. (2006). The perceived social impacts of the 2006 football world cup on Munich residents. Journal of Sport \& Tourism,11(2), 129-52.

40. Organ, K., Koenig-Lewis, N., Palmer, A., \& Probert, J. (2015). Festivals as agents for behavior change: A study of food festival engagement and subsequent food choices. Tourism Management, 48(1), 84-99.

41. Pranić, L., Petrić, L., Cetinić, L. (2012). Host population perceptions of the social impacts of sport tourism events in transition countries. Evidence from Croatia. Croatia. International Journal of Event and Festival Management, 3(3), 236-256.

42. Prayag, G., Hosany,S., Nunkoo, R., Alders, T. (2013). London residents' support for the 2012 Olympic games: The mediating effect of overall attitude. Tourism Management, 36(1), 629-640.

43. Quinn, B. (2006). Problematizing 'festival tourism': Arts festivals and sustainable development in Ireland. Journal of Sustainable Tourism, 14(3), 288-306.

44. Rao, V. (2001). Celebrations as social investments: Festival expenditures, unit price variation and social status in rural India. Journal of Development Studies, 38(1), 71-97.

45. Saunders, M., Lewis, P., Thornhill, A. (2012). Research methods for business Students $6^{\text {th }}$ edition, Pearson Education Limited.

46. Sheldon, P.J., Var, T. (1984). Resident attitudes to tourism in North Wales. Tourism Management, 5(1), 40-47.

47. Small, K., Edwards, D., Sheridan, L., (2005). A flexible framework for evaluating the socio-cultural impacts of a (small) festival. Journal of Event Management Research, 1(1), 66-77.

48. Song, Z., Xing, L., Chathoth, P. K. (2015). The effects of festival impacts on support intentions based on residents' ratings of festival performance and satisfaction: a new integrative approach. Journal of Sustainable Tourism, 23(2), 316-337. 
49. Van Winkle, C.M., Woosnam, K.M. (2014). Sense of community and perceptions of festival social impacts. International Journal of Event Management, 5(1), 22-38.

50. Williams, D. R., McDonald, C. D., Riden, C. M., Uysal, M. (1995). Community attachment, regional identity and resident attitudes towards tourism. Paper presented at the 26th Annual Travel and Tourism Research Association Conference, Wheat Ridge, CO.

51. Yolal, M., Çetinel, F., Uysal, M. (2009). An Examination of Festival Motivation and Perceived Benefits Relationship: Eskișehir International Festival. Journal of Convention \& Event Tourism, 10(4), 276-291.

52. Yolal, M., Gursoy, D., Uysal, M., Kim, H. L., Karacaoğlu, S. (2016). Impacts of festivals and events on residents' well-being. Annals of Tourism Research, 61, 1-18.

53. Yolal, M., Woo, E., Cetinel, F., Uysal, M., (2012). Comparative research of motivations across different festival products. International Journal of Event and Festival Management, 3(1), 66-80.

54. Yu, A.H., Ke, H. (2010). An exploratory study of the application of sense of community in a local festival. Northeastern Recreation Research Symposium, GTR-NRS-P-94, 7883.

55. Zhou, Y., Ap, J. (2009). Residents' perceptions towards the impacts of the Beijing 2008 Olympic games. Journal of Travel Research, 48(1), 78-91. 